\title{
CARACTERIZAÇÃO FÍSICO-QUÚMICA DE SOLO RASO A DESENVOLVIDO (ASSOCIACCÃO NEOSSOLO QUARTZARÊNICO) E SOLO HIDROMÓRFICO (ASSOCIAÇÃO GLEISSOLO HÁPLICO): O CONTEXTO AMBIENTAL DA BACIA HIDROGRÁFICA DO RIO DOS CACHORROS, SÃO LUÍS-MA
}

\author{
MELINA FUSHIMI \\ Doutora em Geografia. Pós-Doutorado pela Universidade Estadual de Campinas. Professora \\ do Programa de Pós-graduação em Geografia, Natureza e Dinâmica do Espaço - Universidade \\ Estadual do Maranhão, Campus de São Luís ${ }^{1}$ \\ fushimi.melina@gmail.com

\section{REGINA CÉLIA DE OLIVEIRA} \\ Doutora em Geociências e Meio Ambiente. Professora do Programa de Pós Graduação em \\ Geografia da Universidade Estadual de Campinas ${ }^{2}$ \\ regina5@unicamp.br
}

\section{GILBERLENE SERRA LISBOA}

Mestre em Geografia. Doutoranda em Geografia do Programa de Pós Graduação em Geografia da Universidade Federal do Rio de Janeiro ${ }^{3}$

\section{gilberlene serra@yahoo.com.br}

\section{BRUNO SANTOS FERREIRA}

Técnico em Meio Ambiente pelo Instituto Federal de Educação, Ciência e Tecnologia do Maranhão, Campus São Luís - Maracanã. Graduando em Geografia da Universidade

Estadual do Maranhão, Campus de São Luís ${ }^{1}$

brunosantosferreira.1999@gmail.com

\section{PAULO ZIDANE FERREIRA DA SILVA}

Graduando em Geografia da Universidade Estadual do Maranhão, Campus de São Luís1 zidanefsilva@hotmail.com

\section{JOÃO OSVALDO RODRIGUES NUNES}

Doutor em Geografia e Livre Docente pela Universidade Estadual Paulista, Campus de Presidente Prudente. Professor do Programa de Pós-Graduação em Geografia da

Universidade Estadual Paulista, Campus de Presidente Prudente 4

joao.o.nunes@unesp.br

RESUMO: O artigo tem por objetivo caracterizar as propriedades físico-químicas de um solo raso a desenvolvido (associação Neossolo Quartzarênico) e de um solo hidromórfico (associação Gleissolo Háplico) sob o contexto ambiental da bacia hidrográfica do rio dos Cachorros, São Luís-MA. Os materiais e métodos contaram com a caracterização dos solos em dois pontos representativos, em que realizou-se trabalhos de campo e análises laboratoriais físicas e químicas. Além disso, foram feitos documentos cartográficos, com destaque aos perfis morfodinâmicos A-B e C-D. Os resultados mostraram que os solos são moderadamente a fortemente ácidos e arenosos, indicando valores superiores a $872 \mathrm{~g} . \mathrm{Kg}^{-1}$ de areia e classes texturais "Areia" e "Areia franca". O solo raso a desenvolvido apresenta-se degradado diante da atividade de extração mineral. Consequentemente, a vegetação e o horizonte superficial foram removidos com baixa presença de matéria orgânica no solo. $\mathrm{O}$ solo hidromórfico, sob formação vegetal secundária, detém maior quantidade de matéria orgânica.

Palavras-chave: solos; propriedades físico-químicas; contexto ambiental.

${ }^{1}$ Endereço para correspondência: Cidade Universitária Paulo VI, Tirirical - CEP: 65055-970 - São Luís, MA - Brasil.

2 Endereço para correspondência: Instituto de Geociências da UNICAMP, Departamento de Geografia. Cidade Universitária- Zeferino Vaz - Distrito de Barão Geraldo - CEP: 13083-970 - Campinas, SP - Brasil.

3 Endereço para correspondência: Lagesolos, Departamento de Geografia, Bloco I, sala o9, Ilha do Fundão, Cidade Universitária - CEP: 21044-020 - Rio de Janeiro, RJ - Brasil.

4 Endereço para correspondência: Rua Roberto Simonsen, 305 - Centro Universitário - CEP: 19060-900, Presidente Prudente-SP - Brasil. 


\section{PHYSICO-CHEMICAL CHARACTERIZATION OF SHALLOW TO DEVELOPED SOIL (ASSOCIATION NEOSSOLO QUARTZARÊNICO) AND HYDROMORPHIC SOIL (ASSOCIATION GLEISSOLO HÁPLICO): THE ENVIRONMENTAL CONTEXT OF THE HYDROGRAPHIC BASIN OF CACHORROS RIVER, SÃO LUÍS-MA}

ABSTRACT: The assignment aimed to characterize the physico-chemical properties of a shallow to developed soil (association Neossolo Quartzarênico) and a hydromorphic soil (association Gleissolo Háplico) by the environmental context of the hydrographic basin of Cachorros river, São Luís-MA. The materials and methods included the characterization of soils in two representative points which fieldwork and physical and chemical laboratory analysis were carried out. Moreover, cartographic documents were elaborated with emphasis on morphodynamic profiles A-B and C-D. The results showed that the soils are moderately to strongly acid and sandy, indicating values higher than 872 g.Kg-1 of sand and textural classes "Sand" and "Loamy sand". The shallow to developed soil are degraded in view of activity of mineral extraction. As a consequence, the vegetation and surface horizon were removed with low organic matter in the soil. The hydromorphic soil, under vegetal formation, has highest quantity of organic matter.

Keywords: soils; physico-chemical properties; environmental context.

\section{CARACTERIZACIÓN FÍSICO-QUÍMICA DEL SUELO RASO Y DESARROLLADO (ASOCIACIÓN NEOSUELO CUARZARÉNICO) Y SUELO HIDROMÓRFICO (ASOCIACIÓN GLEISUELO HÁPLICO): LO CONTEXTO AMBIENTAL DE LA CUENCA HIDROGRÁFICA DEL RIO DE LOS CACHORROS, SÃO LUÍS-MA}

RESUMEN: El artigo tiene como objetivo caracterizar las propiedades físico-químicas de un suelo raso y desarrollado (asociación Neosuelo Cuarzarénico) y del suelo hidromórfico (asociación Gleisuelo Háplico) bajo lo contexto ambiental de la cuenca hidrográfica del rio de los Cachorros, São Luís-MA. Los materiales y métodos contaran con la caracterización de los suelos en dos pontos representativos en que se realizó lo trabajo del campo y analices de laboratorio físicas y químicas. Además, fueron realizados documentos cartográficos con destaque a los perfiles morfo dinámicos A-B y C-D. Los resultados mostraran que los suelos son moderadamente a fuertemente ácidos y arenosos, indicando valores superiores a $872 \mathrm{~g} . \mathrm{Kg}^{-1}$ de arena y clases texturales "Arena" y "Arenoso franco". El suelo raso y desarrollado se muestra degradado delante de la actividad de la extracción mineral. Consecuentemente, la vegetación y el horizonte superficial fueran removidos con baja presencia de la materia orgánica en lo suelo. Lo suelo hidromórfico, bajo formación vegetal secundaria, detén mayor cuantidad de materia orgánica.

Palabras clave: suelos; propiedades físico-químicas; contexto ambiental.

\section{Introdução}

A ciência geográfica caracteriza-se pela conexão entre sociedade e natureza, sendo esta, no atual momento histórico, ressignificada na concepção do conceito de ambiente enquanto natureza transfigurada ou segunda natureza (SUERTEGARAY; DE PAULA, 2019). Sob o olhar geográfico, as formas e os processos que ocorrem no ambiente identificam-se como híbridos (SUERTEGARAY, 2002) e podem ser analisados a partir de diversos aspectos, dentre eles, o solo.

O solo, compreendido como um sistema dinâmico e aberto, encontra-se na interface entre necessidades humanas, atividades sociais e conservação dos ecossistemas. Lal (2007), Lepsch (2011) e Brady e Weil (2013) discorrem sobre as variadas funções do solo no ambiente, por exemplo, substrato da urbanização e das práticas sociais, fonte de alimento, abastecimento de água mediante recarga de aquífero e meio para crescimento de plantas.

Historicamente, no século XIX, pesquisadores da escola russa verificaram em campo que os diferentes tipos de solos resultam da ação conjunta de fatores (FREIRE, 2006; LEPSCH, 2010). Nessa perspectiva, Lepsch (2010) afirma que o solo é a coleção de corpos naturais dinâmicos, que contém matéria viva e é resultante da ação do clima e da biosfera sobre a rocha, cuja transformação em solo se realiza durante certo tempo e é influenciada 
pelo relevo. Vale ressaltar que os organismos são compostos por microrganismos, vegetais superiores, animais, ser humano e sociedade.

Os fatores de formação material de origem, clima, organismos, tempo e relevo, ao condicionar os processos pedológicos, principalmente adição, transformação, translocação e remoção (ou perda), determinam a morfologia e as características físicas, químicas e mineralógicas do solo (LEPSCH, 2011).

Nesse sentido, o presente artigo objetivou caracterizar as propriedades físicoquímicas de um solo raso a desenvolvido (associação Neossolo Quartzarênico) e de um solo hidromórfico (associação Gleissolo Háplico) sob o contexto ambiental da bacia hidrográfica do rio dos Cachorros, São Luís-MA.

Os atributos físicos (argila, silte e areia) e químicos (potencial Hidrogeniônico em água, potencial Hidrogeniônico em $\mathrm{KCl}$, matéria orgânica, fósforo, potássio, cálcio, magnésio, alumínio, acidez potencial, soma de bases trocáveis, capacidade de troca de cátions, saturação da CTC por bases e saturação por alumínio) na conjuntura ambiental (litologia, precipitação, relevo, presença ou ausência de cobertura vegetal e uso da terra) auxiliam a diferenciação e, por conseguinte, a caracterização dos solos em estudo.

\section{Caracterização da área de estudo}

A bacia hidrográfica do rio dos Cachorros situa-se ao Sul de São Luís e da Ilha do Maranhão que compreende os municípios de São Luís, Paço do Lumiar, São José de Ribamar e Raposa (Figura 1).

Litoestratigraficamente, a área de estudo constitui-se por sedimentos do Terciário, em particular, arenoargilosos (fácies arenosas e arenoargilosas) da Formação Barreiras e por sedimentos arenosos inconsolidados e argilosos da Formação Açuí e relacionados ao Holoceno do Quaternário (RODRIGUES et al., 1994; PEREIRA, 2006).

Na Formação Barreiras ocorrem as formas de relevo denudacionais tabuleiros com topos planos, colinas esparsas e vertentes côncavo-convexas em Argissolos (MARANHÃO, 1998; EMBRAPA, 2006; 2018; SILVA, 2012). Com base em trabalhos de campo, descrições gerais e morfológicas e análises físicas e químicas, verificou-se também a ocorrência de solos com características de Neossolos Quartzarênicos. Diante da Formação Açuí têm-se as formas agradacionais planícies de maré e planícies fluviais, com Solos Indiscriminados de Mangue e Gleissolos Háplicos, respectivamente (MARANHÃO, 1998; EMBRAPA, 2006; 2018; SILVA, 2012).

A formação vegetal primária da região caracteriza-se por floresta Amazônica Maranhense transicional para floresta de babaçu e áreas com vegetação de mangue (EMBRAPA, 1986; VALLADARES, 2009). No atual momento histórico, no recorte de trabalho, as florestas foram substituídas por vegetação secundária mista de capoeira e zonas industriais, residenciais e rurais (SÃO LUÍS, 1992; MARANHÃO, 2010; CASTRO; PEREIRA, 2012). Além do mais, a partir de trabalhos de campo e de imagens do Google Earth Pro $囚 ~ e$ do satélite Sentinel-2, datadas de 2019 e 2017, nessa ordem, constatou-se cobertura de gramínea.

Em relação ao clima de São Luís, sob o contexto dos deslocamentos anuais da Zona de Convergência Intertropical (ZCIT) destaca-se o regime de chuvas, com um período chuvoso que concentra-se, em geral, entre janeiro e junho, enquanto o período de estiagem abrange julho a dezembro (UFMA, 2009; PINHEIRO; ARAÚJO, 2019). Cabe mencionar que, ao analisar a Tabela 1, observa-se que a diminuição significativa da quantidade pluviométrica inicia-se no mês de agosto. 
Figura 1. Localização da bacia hidrográfica do rio dos Cachorros, São Luís-MA.

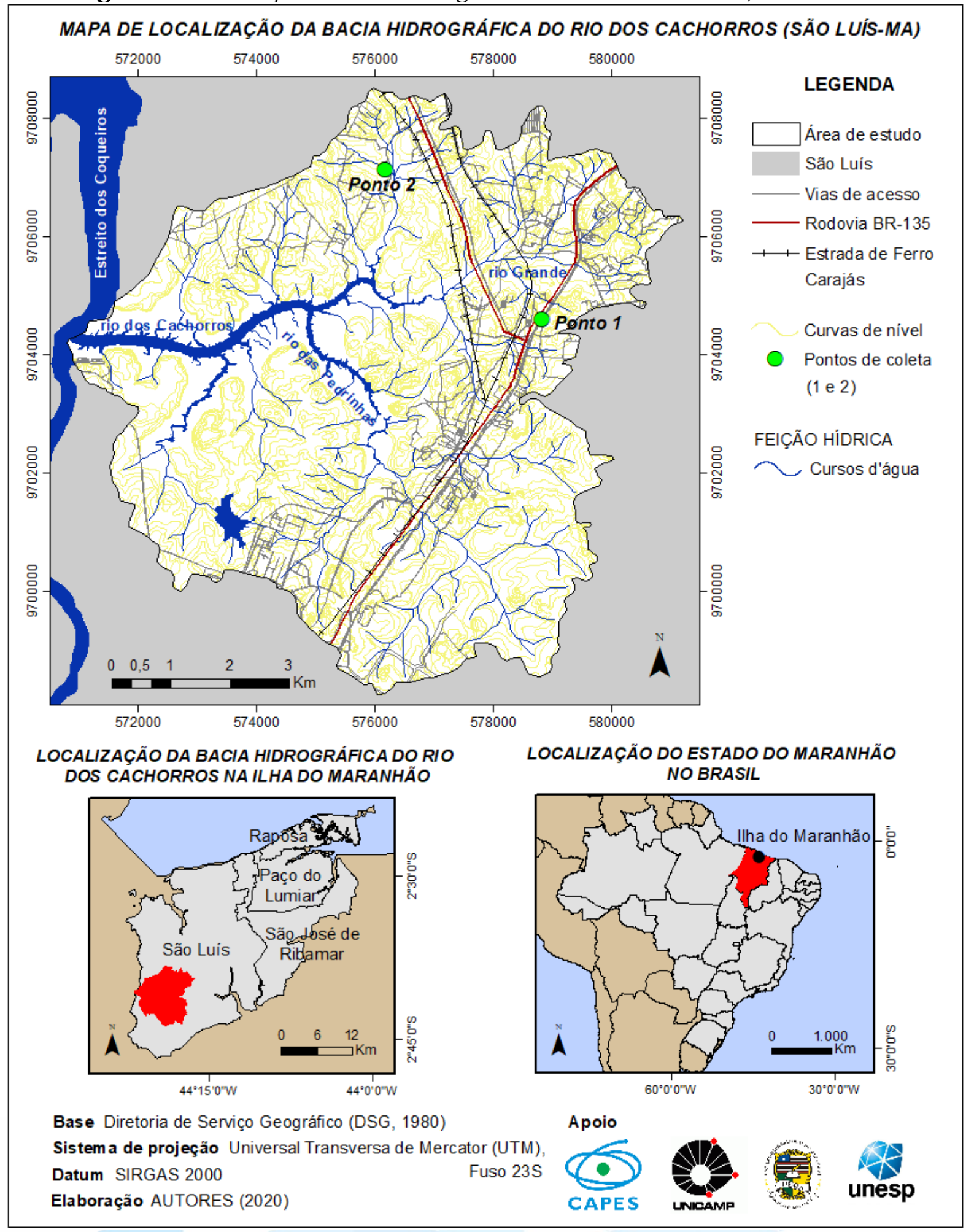

Elaboração: Autores, 2020. 
Tabela 1. Valores da precipitação média para os meses de janeiro a dezembro entre 2015 a 2019, médias mensais de 5 anos e série histórica de 30 anos do município de São Luís.

\begin{tabular}{|c|c|c|c|c|c|c|c|}
\hline \multirow[t]{2}{*}{ Mês } & 2015 & 2016 & $\mathbf{2 0 1 7}$ & 2018 & 2019 & $\begin{array}{c}\text { Média de } \\
5 \text { anos }\end{array}$ & $\begin{array}{c}\text { Média de 3o } \\
\text { anos (1981- } \\
\text { 2010) }\end{array}$ \\
\hline & \multicolumn{7}{|c|}{$\mathrm{mm}$} \\
\hline Janeiro & 30,2 & 204,5 & 380 & 253 & 327,9 & 239,1 & 227,5 \\
\hline Fevereiro & 90,7 & 140,8 & 355,4 & 531 & 521,6 & 327,9 & 326,3 \\
\hline Março & 425,9 & 362,1 & 442,8 & 251,4 & 818,2 & 460,1 & 456,4 \\
\hline Abril & 366,5 & 327,4 & 362,1 & 478,2 & 433,7 & 393,6 & 448,8 \\
\hline Maio & 399,7 & 264,9 & 329,9 & 374,2 & 226,7 & 319,1 & 300,3 \\
\hline Junho & 106,7 & 133,4 & 120,6 & 106,3 & 218,3 & 137,1 & 172,5 \\
\hline Julho & 75,9 & 52,1 & 201,4 & 75,4 & 107,4 & 102,4 & 118,1 \\
\hline Agosto & 0 & 13,4 & 4,8 & 27,2 & 3,4 & 9,8 & 29,9 \\
\hline Setembro & $\mathrm{O}$ & 1,8 & $\mathrm{O}$ & 11,6 & 4,9 & 3,7 & 6,3 \\
\hline Outubro & $\mathrm{O}$ & $\mathrm{O}$ & 1,2 & 4,2 & 2,1 & 1,5 & 6,2 \\
\hline Novembro & 0,3 & O & 0,6 & 8,5 & 16 & 5,1 & 10,6 \\
\hline Dezembro & 11,3 & 42,9 & 63,2 & 209,8 & 72,8 & 80,0 & 73,5 \\
\hline Total & 1507,2 & 1543,3 & 2262 & 2330,8 & 2753 & 2079,3 & 2176,4 \\
\hline
\end{tabular}

Fonte: INMET (2020).

\section{Materiais e métodos}

\section{Caracterização dos solos}

A escolha dos solos de estudo (Pontos 1 e 2) considerou as formas de relevo, as quais constituem um dos fatores de formação e de diferenciação dos solos.

Em trabalhos de campo, no Ponto 1 realizou-se descrição geral e morfológica e coleta de duas amostras de solo em perfil exposto por processo de ravinamento (Figura 2A), segundo os manuais técnicos de Pedologia do Instituto Brasileiro de Geografia e Estatística (IBGE, 2015a; 2015b).

No Ponto 2 ocorreu a descrição geral e devido à ausência de cortes ou barrancos e sua localização no fundo de vale, uma amostra do horizonte superficial foi coletada $(15 \mathrm{~cm}$ de profundidade) ao manusear o trado do tipo holandês (Figura 2B), conforme recomenda o manual de descrição e coleta de solo no campo de Lemos e Santos (1996) e IBGE (2015a; 2015b). Sob estas circunstâncias, somente a descrição morfológica relacionada à cor foi feita no Ponto 2.

Posteriormente, as amostras de solo passaram por análises de laboratório físicas e químicas. A análise física determinou a textura, isto é, a participação das partículas constituintes do solo (argila, silte e areia), separadas por tamanho. Para tanto, adaptou-se os procedimentos do manual de métodos de análise de solo da Empresa Brasileira de Pesquisa Agropecuária (EMBRAPA, 1997). Os resultados obtidos agruparam-se em classes texturais por meio do triângulo textural do IBGE (2015a) e a areia foi fracionada através do agitador de peneiras, sendo as areias presentes em cada peneira pesadas e, considerando-se a massa total, têm-se as quantidades de cada fração: muito grossa, grossa, média, fina e muito fina. 
Figura 2. Coleta de amostras de solo em ravina (A) e com o trado holandês (B).

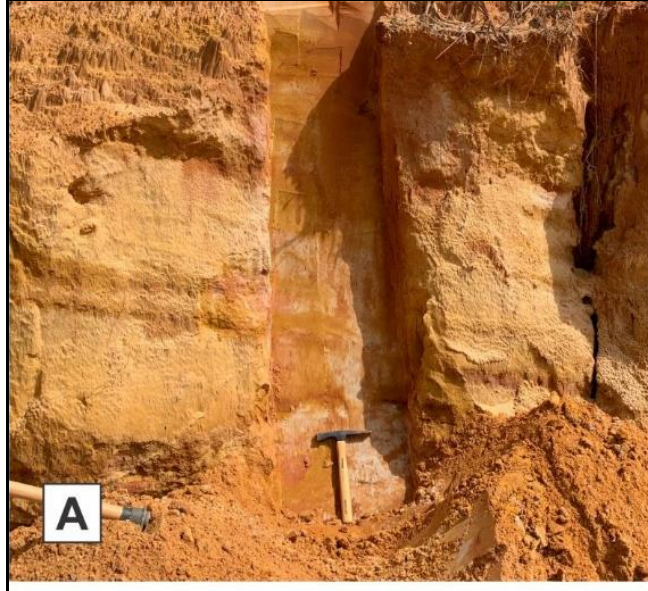

A. Ravina

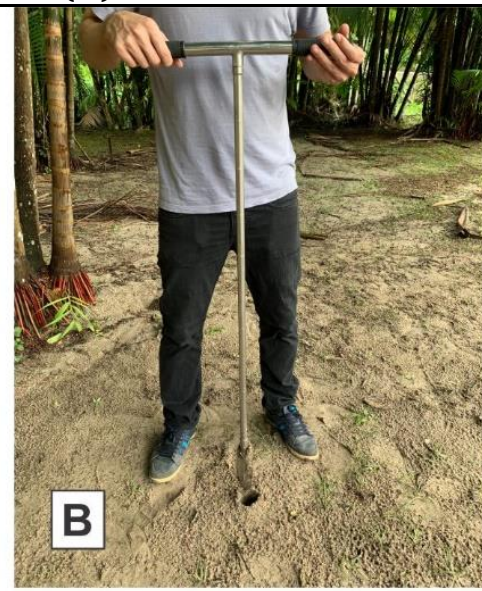

B. Trado holandês

Elaboração: Autores, 2019.

As análises químicas foram feitas de acordo com o manual de métodos de análise de solo (EMBRAPA, 2017) para mensurar as propriedades potencial Hidrogeniônico em água (pH em água), potencial Hidrogeniônico em $\mathrm{KCl}(\mathrm{pH} \mathrm{KCl})$, fósforo $(\mathrm{P})$, potássio $(\mathrm{K})$, cálcio $(\mathrm{Ca})$, magnésio $(\mathrm{Mg})$, alumínio $(\mathrm{Al})$ e acidez potencial $(\mathrm{H}+\mathrm{AL})$. Ao quantificar a matéria orgânica (MO) utilizou-se os métodos de análise química, mineralógica e física de solos do Instituto Agronômico de Campinas (IAC, 2009). Com base nesses parâmetros, calculou-se a soma de bases trocáveis (SB), a capacidade de troca de cátions (CTC), a saturação da CTC por bases (V) e a saturação por alumínio (m). A classificação do pH em água considerou os critérios adotados pela Embrapa (2018).

A partir das informações obtidas nos trabalhos de campo, nas análises físicas e químicas e em decorrência das alterações dos atributos pedológicos pelos usos da terra, adaptaram-se as classes de solos propostas por Trentin (2011), Fushimi (2012) e pelo Sistema Brasileiro de Classificação de Solos até o segundo nível categórico (EMBRAPA, 2018) para os solos analisados, como demonstra o Quadro 1:

Quadro 1. Adaptação das classes de solos para os solos de estudo.

\begin{tabular}{|c|c|c|c|}
\hline $\begin{array}{c}\text { Classes de } \\
\text { solos } \\
\text { propostas por } \\
\text { Trentin (2011) }\end{array}$ & $\begin{array}{l}\text { Classes de solos } \\
\text { propostas por } \\
\text { Fushimi (2012) }\end{array}$ & $\begin{array}{c}\text { Classes de } \\
\text { solos } \\
\text { propostas } \\
\text { pela Embrapa } \\
(\mathbf{2 0 1 8 )}\end{array}$ & $\begin{array}{c}\text { Classes de solos } \\
\text { adaptadas para os } \\
\text { solos de estudo }\end{array}$ \\
\hline $\begin{array}{l}\text { Solos rasos de } \\
\text { altitudes } \\
\text { elevadas }\end{array}$ & $\begin{array}{l}\text { Solos rasos - } \\
\text { associação } \\
\text { Neossolos } \\
\text { Regolíticos }\end{array}$ & $\begin{array}{l}\text { Neossolos } \\
\text { Regolíticos }\end{array}$ & $\begin{array}{c}\text { Solos rasos a } \\
\text { desenvolvidos - } \\
\text { associação Neossolos } \\
\text { Quartzarênicos }\end{array}$ \\
\hline $\begin{array}{c}\text { Solos } \\
\text { hidromórficos }\end{array}$ & $\begin{array}{c}\text { Solos hidromórficos } \\
\text { - associação } \\
\text { Planossolos e } \\
\text { Gleissolos }\end{array}$ & $\begin{array}{c}\text { Planossolos } \\
\text { Gleissolos }\end{array}$ & $\begin{array}{c}\text { Solos hidromórficos - } \\
\text { associação Gleissolos } \\
\text { Háplicos }\end{array}$ \\
\hline
\end{tabular}

Fonte: Trentin (2011), Fushimi (2012) e Embrapa (2018).

Elaboração dos documentos cartográficos

Os documentos cartográficos foram elaborados no software ArcGIS®, versão 10.5, com a base planialtimétrica disponibilizada pela Diretoria de Serviço Geográfico (DSG, 1980), cujas curvas de nível possuem equidistâncias de cinco metros e escala 1:10.000. 
No mapa de hipsometria, por intermédio das ferramentas "Create TIN From Features" e "TIN to Raster", criou-se uma estrutura de grade triangular TIN (Triangular Irregular Networks) e a opção "Elevation" foi selecionada. A realização dos perfis morfodinâmicos A-B e C-D basearam-se em Ruggiero et al. (2006) e Fushimi (2012).

\section{Resultado e discussão}

Com a finalidade de auxiliar a contextualização ambiental foram elaborados os perfis morfodinâmicos A-B e C-D que representam os solos em estudo ao longo de perfis topográficos e cujas localizações no mapa de hipsometria da bacia hidrográfica do rio dos Cachorros, São Luís-MA, apresentam-se na Figura 3.

Figura 3. Localização dos perfis morfodinâmicos A-B e C-D no mapa de hipsometria da bacia hidrográfica do rio dos Cachorros, São Luís-MA.

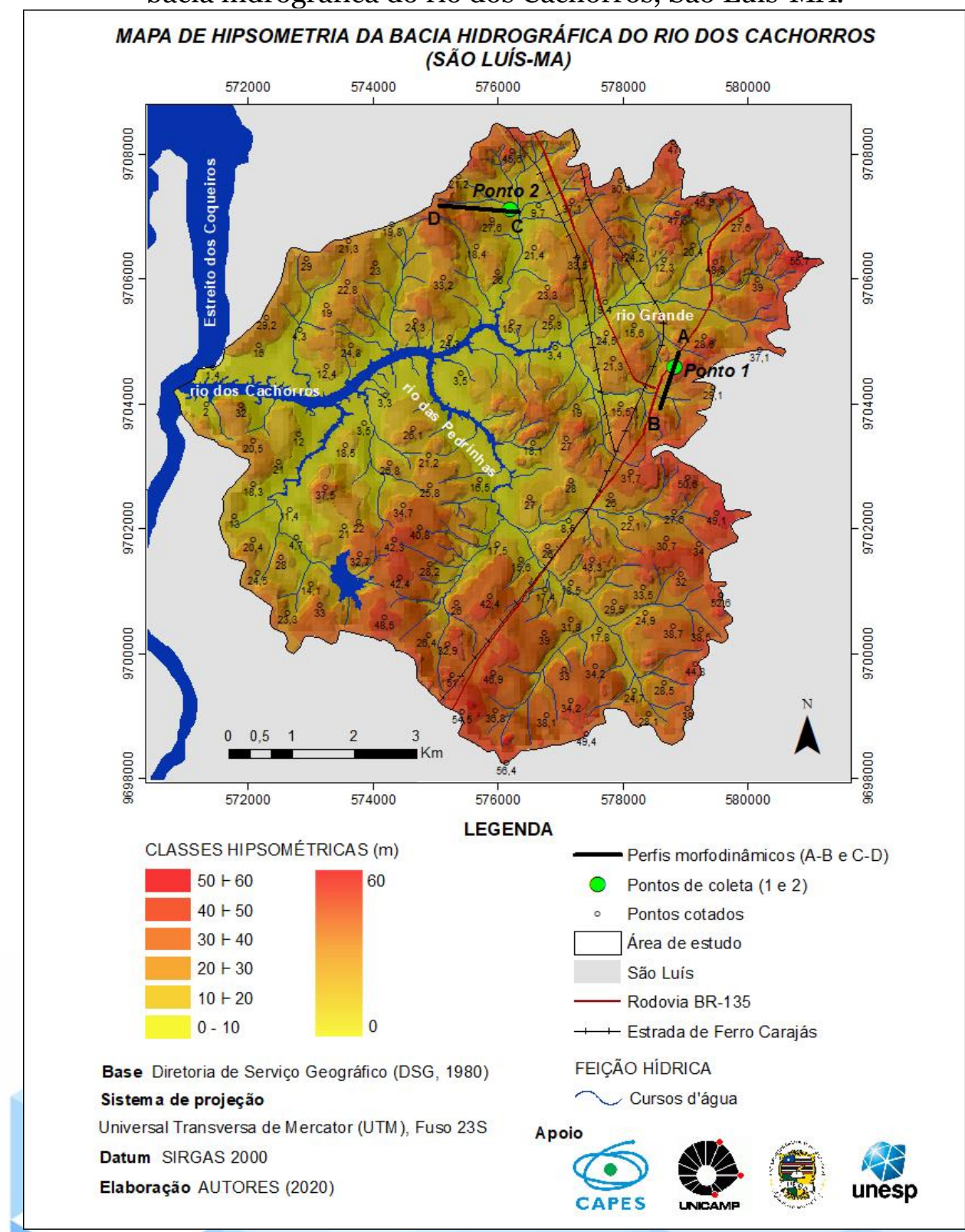

Elaboração: Autores, 2020.

Melina Fushimi et al. Caracterização físico-química de solo raso a desenvolvido (...)

Brazilian Geographical Journal: Geosciences and Humanities research medium, Ituiutaba, v. 11, n. 1, p. 4-18, jan./jul. 2020. Página $\mid 10$ 
No perfil morfodinâmico A-B (Figura 4), a planície fluvial de um afluente do rio dos Cachorros relaciona-se aos depósitos flúviolacustres da Formação Açuí, enquanto as formas de relevo colina esparsa e tabuleiro com topo plano pertencem à Formação Barreiras. No Ponto 1, diante dos sedimentos arenoargilosos da Formação Barreiras em colina esparsa e altitude de 30 m tem-se solo raso a desenvolvido - associação Neossolo Quartzarênico.

Figura 4. Perfil morfodinâmico A-B e solo raso a desenvolvido - associação Neossolo Quartzarênico (Ponto 1).

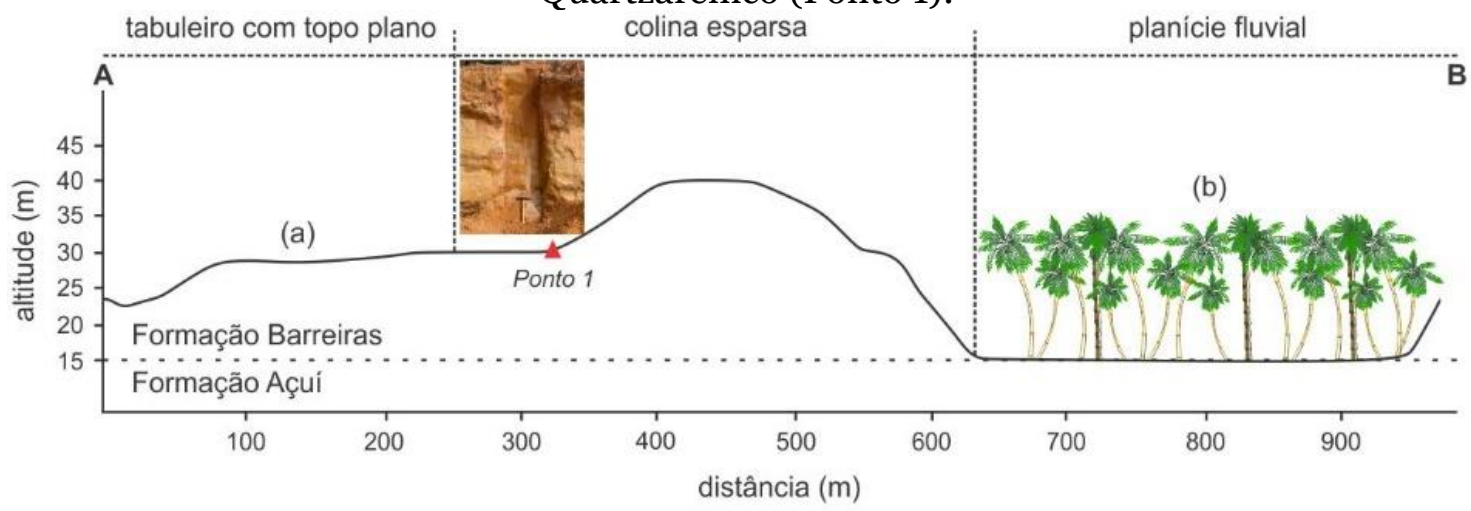

(a) ausência de vegetação; (b) vegetação secundária mista de capoeira. Elaboração: Autores, 2020.

O horizonte superficial A e a cobertura vegetal do Ponto 1 foram removidos pela extração de areia empregada na construção civil. De acordo com Sathler et al. (2005), Castro e Santos (2012) e Castro e Pereira (2012), das empresas de extração mineral existentes em São Luís, $72 \%$ estão instaladas na bacia hidrográfica de estudo, em que as atividades são responsáveis por transformações no ambiente ao acelerar processos erosivos. No ponto em análise observou-se erosão laminar e linear (sulcos e ravinas) em avançado estágio de evolução (Figura 5).

Figura 5. Erosão linear e laminar. A seta indica a direção do escoamento superficial.

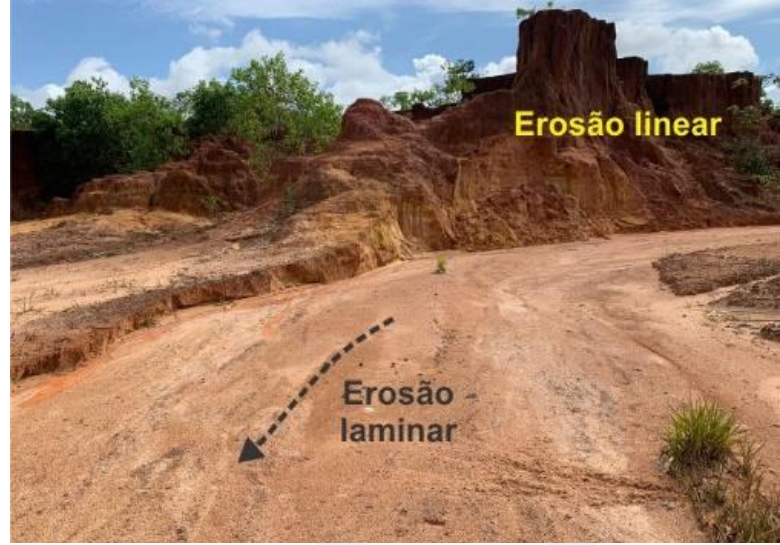

Foto: Autores, 2019.

O perfil de solo raso a desenvolvido (Quadro 2) detém sequência de horizontes $\mathrm{C}_{1}-\mathrm{C} 2$, subdivididos por diferenças texturais e transição difusa e associa-se ao Neossolo Quartzarênico. Esta classe indica textura areia ou areia franca em todos os horizontes até, no mínimo, $150 \mathrm{~cm}$ de profundidade ou até um contato lítico ou lítico fragmentário (EMBRAPA, 2018). Além disso, por ser muito arenosa e porosa (poros médios e abundantes), possui baixa capacidade de armazenar água e nutrientes para as plantas (LEPSCH, 2011). 
Quadro 2. Descrição geral e morfológica do solo do Ponto 1.

\begin{tabular}{|c|c|c|c|}
\hline \multicolumn{4}{|c|}{ Solo raso a desenvolvido - associação Neossolo Quartzarênico } \\
\hline \multicolumn{3}{|c|}{ DESCRIÇÃO GERAL } & \\
\hline \multirow{2}{*}{\multicolumn{2}{|c|}{$\begin{array}{c}\text { Data } \\
\text { Localizacão }\end{array}$}} & 10 de junho de 2019 & \\
\hline & & São Luís-MA & \\
\hline \multicolumn{2}{|c|}{$\begin{array}{c}\text { Coordenadas (UTM) } \\
\text { e altitude (m) }\end{array}$} & $\begin{array}{c}578830 \mathrm{~m} \mathrm{E} ; \\
9704585 \mathrm{~m} \mathrm{~S} \text { e } 30 \\
\mathrm{~m}\end{array}$ & \\
\hline \multicolumn{2}{|c|}{$\begin{array}{c}\text { Situação } \\
\text { (tipo de paisagem) }\end{array}$} & Colina esparsa & \\
\hline \multicolumn{2}{|c|}{$\begin{array}{c}\text { Relevo local e } \\
\text { declividade }\end{array}$} & $\begin{array}{c}\text { Suave ondulado e } \\
\text { 10 a } 15 \%\end{array}$ & \\
\hline \multicolumn{2}{|c|}{$\begin{array}{c}\text { Cobertura vegetal } \\
\text { sobre o perfil e uso } \\
\text { atual } \\
\end{array}$} & $\begin{array}{l}\text { Sem cobertura } \\
\text { vegetal e área } \\
\text { industrial }\end{array}$ & \\
\hline \multicolumn{2}{|c|}{$\begin{array}{l}\text { Litologia e unidade } \\
\text { litoestratigráfica }\end{array}$} & $\begin{array}{c}\text { Sedimentos e } \\
\text { Formação Barreiras }\end{array}$ & \\
\hline \multicolumn{2}{|c|}{ Cronologia } & Terciário & \\
\hline \multicolumn{2}{|c|}{$\begin{array}{c}\text { Erosão }^{1} \\
\text { (classe e forma) }\end{array}$} & $\begin{array}{l}\text { Forte e laminar, } \\
\text { sulcos e ravinas }\end{array}$ & \\
\hline \multicolumn{2}{|c|}{ Drenagem } & $\begin{array}{l}\text { Moderadamente } \\
\text { drenado }\end{array}$ & \\
\hline \multicolumn{2}{|c|}{ Descrito e coletado por } & Autores & Foto: Autores, 2019. \\
\hline \multicolumn{4}{|c|}{ DESCRIÇÃO MORFOLÓGICA } \\
\hline Horizonte & & $\mathrm{C} 1$ & $\mathrm{C} 2$ \\
\hline $\begin{array}{l}\text { Profundidade } \\
\text { (cm) }\end{array}$ & & $0-45$ & $46-150+$ \\
\hline $\begin{array}{c}\text { Características } \\
\text { morfológicas }\end{array}$ & $\begin{array}{r}\text { Cor: } \\
\text { seca) } \\
1 \\
\text { Consi } \\
(\mathrm{m}\end{array}$ & $\begin{array}{l}\text { jermelho-claro (10R 6/8, } \\
\text {; Estrutura: fraca média } \\
\text { locos subangulares; } \\
\text { stência: solta (seca), solt } \\
\text { úmida), não plástica } \\
\text { lhada); Poros: médios, } \\
\text { abundantes. }\end{array}$ & $\begin{array}{l}\text { Cor: vermelho-claro (10R 7/6, } \\
\text { seca); Estrutura: fraca média } \\
\text { blocos subangulares; } \\
\text { Consistência: solta (seca), solta } \\
\text { (úmida), não plástica (molhada); } \\
\text { Poros: médios, abundantes. }\end{array}$ \\
\hline
\end{tabular}

${ }^{1}$ Classificação proposta pelo Instituto de Pesquisas Tecnológicas (ALMEIDA FILHO; ALMEIDA, 2016).

O solo é predominantemente arenoso (Tabela 2), com teor de 890,83 g. $\mathrm{Kg}^{-1}$ e 942,22 g. $\mathrm{Kg}^{-1}$ de areia nos horizontes $\mathrm{C}_{1}$ e C2, nessa ordem e classe textural "Areia". Em ambos os horizontes prevalece areia média $\left(535,78 \mathrm{~g} . \mathrm{Kg}^{-1}\right.$ no horizonte $\mathrm{C} 1 \mathrm{e}$ 703,65 g. $\mathrm{Kg}^{-1}$ no horizonte C2), cuja característica relaciona-se às fácies arenosas da Formação Barreiras.

Tabela 2. Resultados da textura e do fracionamento da areia do solo do Ponto 1.

\begin{tabular}{|c|c|c|c|c|c|c|c|c|c|}
\hline \multirow[t]{2}{*}{ Horizonte } & Argila & Silte & Areia & $\begin{array}{l}\text { Areia } \\
\text { muito } \\
\text { grossa }\end{array}$ & $\begin{array}{c}\text { Areia } \\
\text { grossa }\end{array}$ & $\begin{array}{l}\text { Areia } \\
\text { média }\end{array}$ & $\begin{array}{c}\text { Areia } \\
\text { fina }\end{array}$ & $\begin{array}{c}\text { Areia } \\
\text { muito } \\
\text { fina }\end{array}$ & \multirow[t]{2}{*}{$\begin{array}{c}\text { Classe } \\
\text { textural }\end{array}$} \\
\hline & \multicolumn{8}{|c|}{ g. $\mathrm{Kg}^{-1}$} & \\
\hline C1 & 34,67 & 74,50 & 890,83 & $\mathrm{O}$ & 41,32 & 535,78 & 68,26 & 354,64 & Areia \\
\hline $\mathrm{C} 2$ & 4 & 53,78 & 942,22 & 0 & 14,09 & 703,65 & 101,44 & 180,82 & Areia \\
\hline
\end{tabular}


Acerca dos atributos químicos (Tabela 3), o horizonte $\mathrm{C} 1$ é fortemente ácido, com 5 de $\mathrm{pH}$ em água e o horizonte $\mathrm{C} 2 \mathrm{com} 5,7 \mathrm{de} \mathrm{pH}$ em água classifica-se como moderadamente ácido. Em consonância com Freire (2006) e Brady e Weil (2013), a acidez do solo está direta e indiretamente vinculada à quantidade de precipitação pluvial anual, pois a chuva contém uma variedade de ácidos que fornecem íons $\mathrm{H}+$ para o solo. No mais, a lixiviação de cátions não ácidos é acentuada pela grande quantidade de água que percola através do perfil pedológico. A matéria orgânica é inferior a $3,9 \mathrm{~g} \cdot \mathrm{Kg}^{-1} \mathrm{em}$ virtude da ausência de vegetação, uma vez que as plantas superiores são produtoras primárias de matéria orgânica.

Tabela 3. Caracterização química do solo do Ponto 1.

\begin{tabular}{|c|c|c|c|c|c|c|c|c|c|c|c|c|c|}
\hline \multirow[t]{2}{*}{ Horiz. } & \multirow{2}{*}{$\begin{array}{c}\mathbf{p H} \\
\mathbf{H}_{2} \mathbf{O}\end{array}$} & \multirow{2}{*}{$\begin{array}{c}\text { pH } \\
\text { KCl }\end{array}$} & \multirow{2}{*}{$\frac{\text { MO }}{\mathrm{g} \cdot \mathrm{Kg}^{-1}}$} & \multirow{2}{*}{$\frac{\mathbf{P}}{\mathrm{mg} \cdot \mathrm{Kg}^{-}}$} & $\mathbf{K}$ & $\mathbf{C a}$ & Mg & Al & $\mathbf{H}+\mathbf{A l}$ & SB & CTC & $\mathbf{V}$ & $\mathbf{m}$ \\
\hline & & & & & \multicolumn{7}{|c|}{ mmolc.kg. 1} & \multicolumn{2}{|c|}{$\%$} \\
\hline C1 & 5 & 4,6 & $<3,9$ & $<2$ & $<0,5$ & 1 & $<0,4$ & 1 & 3 & 1,1 & 4,1 & 27 & 48 \\
\hline $\mathrm{C} 2$ & 5,7 & 4,8 & $<3,9$ & $<2$ & $<0,5$ & $<0,1$ & $<0,4$ & $<0,02$ & 4 & 0,1 & 4,1 & 2 & 0 \\
\hline
\end{tabular}

Horiz. = horizonte; $\mathrm{pH} \mathrm{H}_{2} \mathrm{O}=$ potencial Hidrogeniônico em água; $\mathrm{pH} \mathrm{KCl}=$ potencial Hidrogeniônico em $\mathrm{KCl} ; \mathrm{MO}=$ matéria orgânica; $\mathrm{P}$ = fósforo; $\mathrm{K}$ = potássio; $\mathrm{Ca}=$ cálcio; $\mathrm{Mg}$ = magnésio; $\mathrm{Al}$ = alumínio; $\mathrm{H}+\mathrm{AL}=$ acidez potencial; $\mathrm{SB}=$ soma de bases trocáveis; $\mathrm{CTC}=$ capacidade de troca de cátions; $\mathrm{V}=$ saturação da CTC por bases; $\mathrm{m}$ = saturação por alumínio.

Elaboração: Autores, 2019.

No perfil morfodinâmico C-D (Figura 6), os relevos denudacionais de colina esparsa e tabuleiro com topo plano compreendem a Formação Barreiras e o relevo de agradação planície fluvial, onde encontra-se o Ponto 2 em cota altimétrica de $11 \mathrm{~m}$, os sedimentos arenosos são recentes (Quaternário) da Formação Açuí, com solos hidromórficos associação Gleissolos Háplicos.

Figura 6. Perfil morfodinâmico C-D e solo hidromórfico - associação Gleissolo Háplico

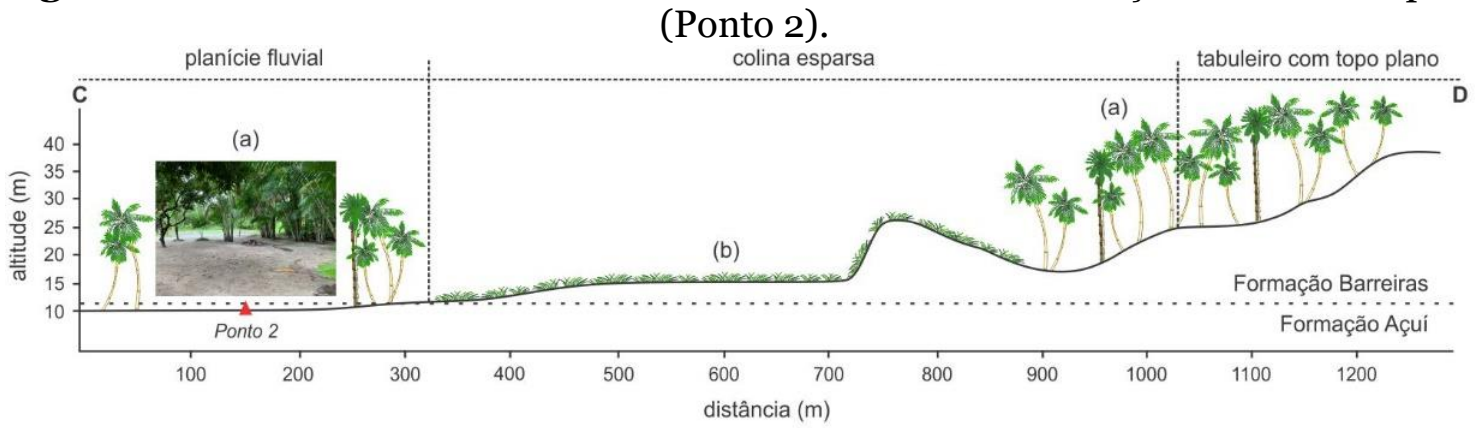

(a) vegetação secundária mista de capoeira; (b) gramínea.

Elaboração: Autores, 2020.

No compartimento da planície fluvial destaca-se a vegetação secundária mista de capoeira (Figura 7) que influencia vários processos no ambiente e, por conseguinte, nos solos, como a pedogênese por meio do intemperismo físico e químico, a proteção direta contra a atuação do splash e do runoff (erosão) e o fornecimento de materiais para a síntese do húmus (MORGAN, 2005; LEPSCH, 2010; 2011; GUERRA, 2009). 


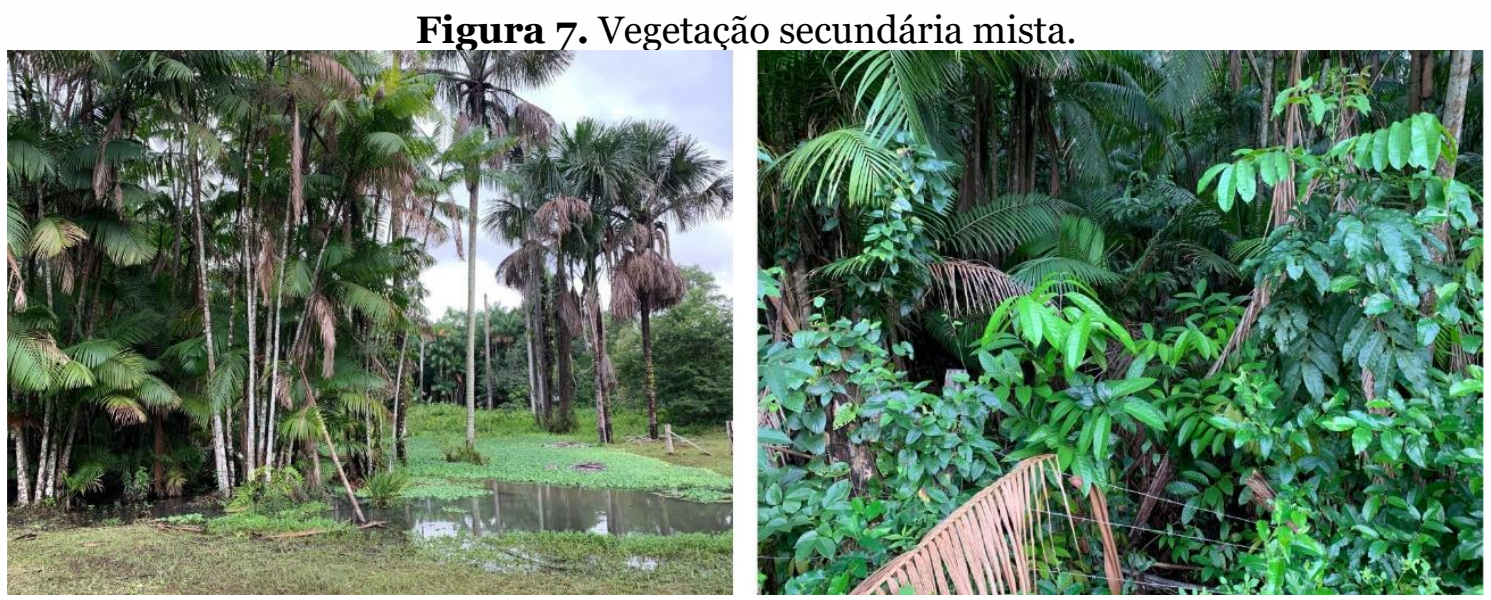

Foto: Autores, 2018.

O solo do Ponto 2 é hidromorfizado (Quadro 3) com horizonte superficial glei e associa-se ao Gleissolo Háplico por não se enquadrar nas classes de Gleissolo Tiomórfico, Sálico e Melânico (EMBRAPA, 2018). Sua disposição no fundo de vale e contato com um dos afluentes do rio dos Cachorros favorecem a saturação por água e a redução do ferro, conferindo coloração acinzentada (FREIRE, 2006).

Quadro 3. Descrição geral e morfológica do solo do Ponto 2.

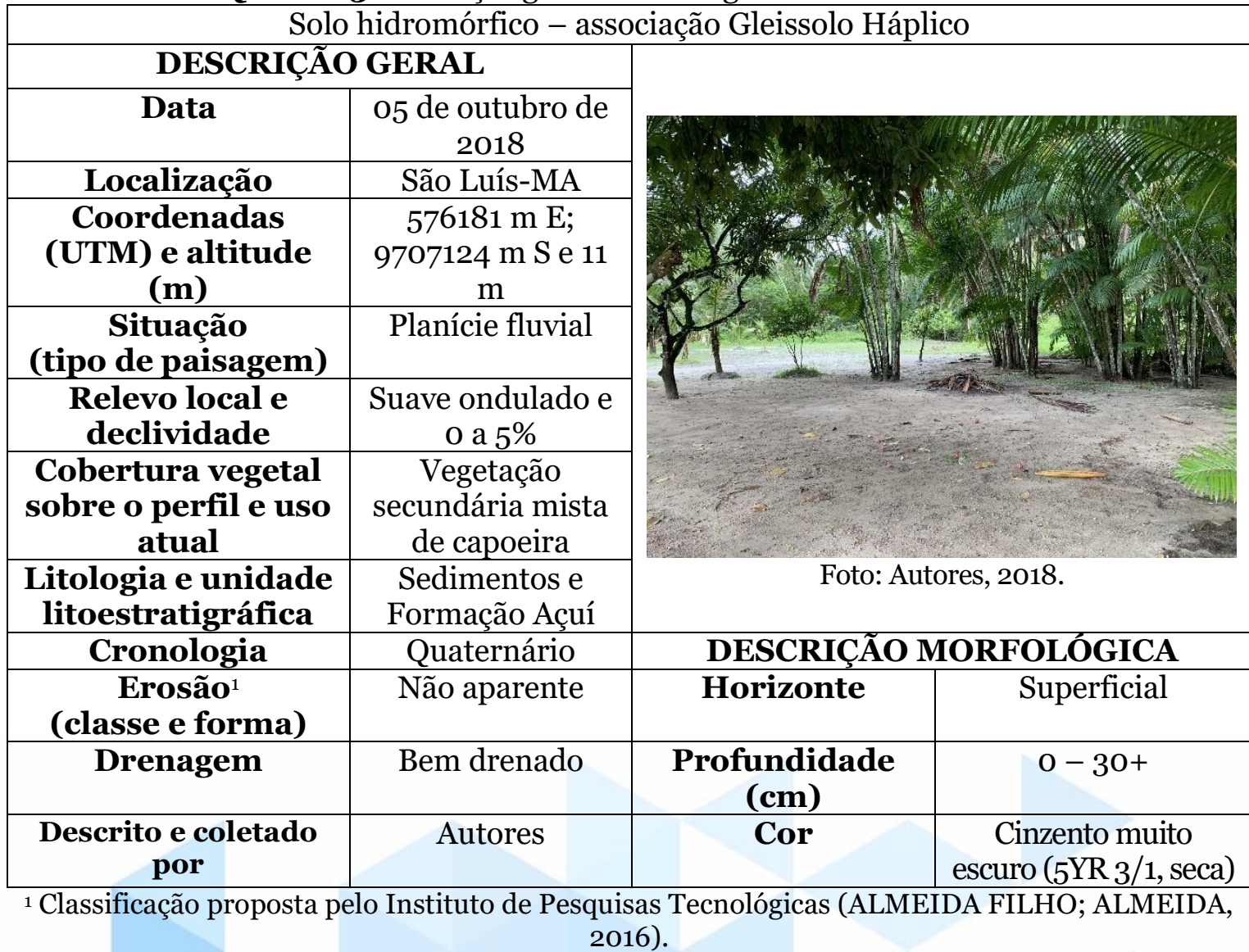

O horizonte superficial é arenoso (Tabela 4), em que a fração areia apresenta-se em grande quantidade (872 g. $\mathrm{Kg}^{-1}$ ) e classe textural "Areia franca". A predominância de areia 
média (463,78 g. $\left.\mathrm{Kg}^{-1}\right)$, seguida de areia fina $\left(375,69 \mathrm{~g} \cdot \mathrm{Kg}^{-1}\right)$ abrange os sedimentos holocênicos da Formação Açuí, bem como material sedimentar advindo de zonas industriais e residenciais a montante, sendo transportados superficialmente, em especial no período chuvoso (entre janeiro e julho).

Tabela 4. Resultados da textura e do fracionamento da areia do solo do Ponto 2.

\begin{tabular}{c|c|c|c|c|c|c|c|c|c}
\hline \multirow{2}{*}{ Horizonte } & Argila & Silte & Areia & $\begin{array}{c}\text { Areia } \\
\text { muito } \\
\text { grossa }\end{array}$ & $\begin{array}{c}\text { Areia } \\
\text { grossa }\end{array}$ & $\begin{array}{c}\text { Areia } \\
\text { média }\end{array}$ & $\begin{array}{c}\text { Areia } \\
\text { fina }\end{array}$ & $\begin{array}{c}\text { Areia } \\
\text { muito } \\
\text { fina }\end{array}$ & $\begin{array}{c}\text { Classe } \\
\text { textural }\end{array}$ \\
\cline { 2 - 6 } & \multicolumn{8}{|c|}{$\mathrm{g} \cdot \mathrm{Kg}^{-1}$} \\
\hline Superficial & 91 & 37 & 872 & 2,85 & 32,92 & 463,78 & 375,69 & 124,76 & Areia franca \\
\hline \multicolumn{8}{c}{ Elaboração: Autores, 2019. }
\end{tabular}

Em relação às propriedades químicas (Tabela 5), o horizonte em análise é fortemente ácido ao dispor de 5,3 pH em água. $\mathrm{O} \mathrm{pH}$ determinado em $\mathrm{KCl}$ possui valores mais baixos que o pH em água, exceto em solos extremamente intemperizados (IBGE, 2015a). Em razão da ocorrência de vegetação têm-se $10 \mathrm{~g} \cdot \mathrm{Kg}^{-1}$ de matéria orgânica, a qual está em constante mudança e é responsável por grande parte da capacidade de troca de cátions, da formação e da estabilização dos agregados do solo, contêm nutrientes para as plantas, dentre outras funções (BRADY; WEIL, 2013).

Tabela 5. Caracterização química do solo do Ponto 2.

\begin{tabular}{|c|c|c|c|c|c|c|c|c|c|c|c|c|}
\hline \multirow[t]{2}{*}{ Horiz. } & \multirow{2}{*}{$\begin{array}{c}\text { pH } \\
\mathbf{H}_{2} \mathbf{O}\end{array}$} & \multirow{2}{*}{$\begin{array}{l}\text { pH } \\
\text { KCl }\end{array}$} & MO & $\mathbf{P}$ & $\mathbf{K}$ & $\mathbf{C a}$ & Mg & $\mathbf{A l}$ & $\mathbf{H}+\mathbf{A l}$ & SB & CTC & \multirow{2}{*}{\begin{tabular}{l|l}
$\mathbf{V}$ & $\mathbf{m}$ \\
\multicolumn{2}{|c}{$\%$}
\end{tabular}} \\
\hline & & & g. $\mathrm{Kg}^{-1}$ & $\underset{1}{\mathrm{mg} \cdot \mathrm{Kg}^{-}}$ & \multicolumn{7}{|c|}{ mmolc.kg.1 } & \\
\hline$\overline{\text { upe }}$ & 5,3 & 4,6 & 10 & 28 &, 5 & 13 & 2 & 1 & 21 & 15,4 & 4 & 2 \\
\hline
\end{tabular}

Horiz. = horizonte; $\mathrm{pH} \mathrm{H}_{2} \mathrm{O}=$ potencial Hidrogeniônico em água; $\mathrm{pH} \mathrm{KCl} \mathrm{=} \mathrm{potencial} \mathrm{Hidrogeniônico}$ em $\mathrm{KCl} ; \mathrm{MO}$ = matéria orgânica; $\mathrm{P}$ = fósforo; $\mathrm{K}$ = potássio; $\mathrm{Ca}=$ cálcio; $\mathrm{Mg}$ = magnésio; $\mathrm{Al}$ = alumínio; $\mathrm{H}+\mathrm{AL}=$ acidez potencial; $\mathrm{SB}=$ soma de bases trocáveis; $\mathrm{CTC}=$ capacidade de troca de cátions; $\mathrm{V}=$ saturação da CTC por bases; $\mathrm{m}$ = saturação por alumínio; Superf. = superficial.

Elaboração: Autores, 2019.

Dessa forma, o contexto ambiental influencia direta e indiretamente as características dos solos, tanto a nível local, quanto em outras áreas. O Ponto 1 situa-se a montante, sem vegetação, com erosão acelerada e encontra-se degradado, constituindo fonte de sedimentos, ao passo que no Ponto 2, localizado a jusante, acontece a deposição de material sedimentar, sobretudo pelo escoamento superficial, ainda que os efeitos da cobertura vegetal atenuem este processo. No período chuvoso, entre os meses de janeiro a julho, a dinâmica erosiva intensifica-se devido ao uso da terra e às propriedades físico-químicas do solos, como predomínio de areia, alta acidez e baixa matéria orgânica do Ponto 1.

\section{Considerações finais}

A conexão entre sociedade e natureza, por meio da inter-relação da litologia, precipitação, relevo, presença ou ausência de cobertura vegetal e uso da terra, resulta em formas e processos híbridos no ambiente e materializa-se nas propriedades físico-químicas dos solos da bacia hidrográfica do rio dos Cachorros, São Luís-MA. Para o presente estudo, caracterizou-se um solo raso a desenvolvido (associação Neossolo Quartzarênico) e um solo hidromórfico (associação Gleissolo Háplico).

Os solos são moderadamente a fortemente ácidos e arenosos, indicando valores superiores a 872 g. $\mathrm{Kg}^{-1}$ de areia e classes texturais "Areia" e "Areia franca". O solo raso a desenvolvido (associação Neossolo Quartzarênico) apresenta-se degradado diante da atividade de extração mineral. Como consequência, a vegetação e o horizonte superficial A 
foram removidos, com baixa presença de matéria orgânica no solo. O solo hidromórfico (associação Gleissolo Háplico) está sob formação vegetal secundária e, por conseguinte, detém maior quantidade de matéria orgânica.

Alguns atributos químicos foram descritos para fins de levantamento de solos e podem auxiliar análises posteriores de diferenciação, de classificação, de mapeamento, de uso e de fertilidade dos solos na bacia hidrográfica de estudo. Além do mais, o presente trabalho poderá complementar pesquisas sobre solo e suas dinâmicas ambientais no contexto de São Luís e da Amazônia Maranhense, assim como subsidiar gestores na elaboração de planos de manejo.

\section{Agradecimentos:}

À Coordenação de Aperfeiçoamento de Pessoal de Nível Superior (CAPES), Processo 88887.200484/2018-oo e à Fundação de Amparo à Pesquisa e ao Desenvolvimento Científico e Tecnológico do Maranhão (FAPEMA), Processo Universal-oo846/2018.

\section{Referências}

ALMEIDA FILHO, G. S. de; ALMEIDA, M. C. J. de. Erosão hídrica do tipo ravina e boçoroca. In: Congresso da Sociedade de Análise de Risco Latino Americana, III, São Paulo, 2016. Anais... São Paulo: ABGE, 2016. p. 1-7.

BRADY, N. C.; WEIL, R. R. Elementos da natureza e propriedades dos solos. 3. ed. Porto Alegre: Bookman, 2013. 686 p.

CASTRO, H. F. R.; PEREIRA, E. D. Cartografia geológico-geotécnica da Bacia Hidrográfica do Rio dos Cachorros. Revista Geonorte, v. 3, n. 4, p. 750-759, 2012.

CASTRO, T. C. S. de; SANTOS, F. R. B. dos. Diagnóstico ambiental da atividade de extração mineral classe 2 na bacia hidrográfica do rio dos cachorros, São Luís - MA, Brasil. Revista Brasileira de Gestão Ambiental, Pombal, v. 6, n. 1, p. 67-76, jan./dez. 2012.

Diretoria de Serviço Geográfico (DSG). Carta preliminar. São Luís. Folhas 37, 38, 39, 44, $45,46,51$ e 52.1980 .

Empresa Brasileira de Pesquisa Agropecuária (EMBRAPA). Levantamento exploratórioreconhecimento de solos do Estado do Maranhão. Rio de Janeiro, EMBRAPASNLCS/SUDENE-DRN, 1986.

Empresa Brasileira de Pesquisa Agropecuária (EMBRAPA). Centro Nacional de Pesquisa de Solos (CNPS). Manual de métodos de análise de solo. 2. ed. Rio de Janeiro, 1997. 212 p. (EMBRAPA - CNPS. Documentos; 1).

Empresa Brasileira de Pesquisa Agropecuária (EMBRAPA). Sistema Brasileiro de Classificação de Solos. 2. ed. Rio de Janeiro: Embrapa-SPI, 2006. 306 p.

Empresa Brasileira de Pesquisa Agropecuária (EMBRAPA). Manual de métodos de análise de solo. 3. ed. rev. ampl. Brasília, DF: Embrapa, 2017. 574 p.

Empresa Brasileira de Pesquisa Agropecuária (EMBRAPA). Sistema Brasileiro de Classificação de Solos. 5. ed. rev. ampl. Brasília, DF: Embrapa, 2018.

FREIRE, O. Solos das regiões tropicais. Botucatu: FEPAF, 2006. 
FUSHIMI, M. Vulnerabilidade Ambiental aos processos erosivos lineares nas áreas rurais do município de Presidente Prudente-SP. 2012. 141 p. Dissertação (Mestrado em Geografia) - Faculdade de Ciências e Tecnologia, Universidade Estadual Paulista, Presidente Prudente, 2012.

GUERRA, A. J. T. Processos Erosivos nas Encostas. In: GUERRA, A. J. T.; SILVA, A. S.; CUNHA, S. B. da (Org.). Geomorfologia: uma atualização de bases e conceitos. 9. ed. Rio de Janeiro: Bertrand Brasil, 2009. p. 149-209.

Instituto Agronômico de Campinas (IAC). Métodos de Análise Química, Mineralógica e Física de Solos do Instituto Agronômico de Campinas. ed. rev. atualizada. Campinas: Instituto Agronômico, 2009. 77 p. (Boletim técnico, 106).

Instituto Brasileiro de Geografia e Estatística (IBGE). Manual Técnico de Pedologia. 3. ed. Rio de Janeiro: IBGE, 2015a. 430 p.

Instituto Brasileiro de Geografia e Estatística (IBGE). Manual Técnico de Pedologia: guia prático de campo. Rio de Janeiro: IBGE, 2015b. 134 p.

Instituto Nacional de Meteorologia (INMET). Normais climatológicas do Brasil. Disponível em: https://portal.inmet.gov.br/. Acesso em: 6 abr. 2020.

LAL, R. World soils and global issues. Soil \& Tillage Research, v. 97, n. 1, p. 1-4, nov. 2007.

LEMOS, R. C.; SANTOS, R. D. Manual de descrição e coleta de solo no campo. 3. ed. Campinas: Sociedade Brasileira de Ciência do Solo, 1996. 84 p.

LEPSCH, I. F. Formação e conservação dos solos. 2. ed. São Paulo: Oficina de Textos, 2010.

LEPSCH, I. F. 19 lições de pedologia. São Paulo: Oficina de Textos, 2011.

MARANHÃO. Macrozoneamento do Golfão Maranhense; Diagnóstico Ambiental da Microrregião da Aglomeração Urbana de São Luís e dos Municípios de Alcântara, Bacabeira e Rosário. São Luís: SEMA. MMA. PNMA, 1998.

MARANHÃO. Diagnóstico ambiental da Ilha do Maranhão - com a implementação do Programa Estadual de Gerenciamento Costeiro do Estado do Maranhão - GERCO Ilha do Maranhão - etapa 1. São Luís, 2010.

MORGAN, R. P. C. Soil erosion \& conservation. 3. ed. Oxford: Blackwell Publishing, 2005 .

PEREIRA, E. D. Avaliação da vulnerabilidade natural à contaminação do solo e do aquiífero do Reservatório Batatã - São Luís - MA. 2006. 133 p. Tese (Doutorado em Geociências) - Instituto de Geociências e Ciências Exatas, Universidade Estadual Paulista, Rio Claro, 2006.

PINHEIRO, J. M.; ARAÚJO, R. R. Impactos do fenomeno El Niño e La Niña no município de São Luís - Maranhão. Revista GeoUECE (Online), v. 8, n. 15, p. 124-136, jul./dez. 2019.

RODRIGUES, T. L. N.; ARAÚJO, C. C. de; CAMOZZATO, E.; RAMGRAB, G. E. (Org.). Programa Levantamentos Geológicos Básicos do Brasil. São Luís. Folha SA.23-Z-A, Cururupu. Folha SA.23-X-C, Estado do Maranhão. Brasília: CPRM, 1994. 
RUGGIERO, P. G. C.; PIVELLO, V. R.; SPAROVEK, G.; TERAMOTO, E.; PIRES NETO, A. G. Relação entre solo, vegetação e topografia em área de cerrado (Parque Estadual de Vassununga, SP): como se expressa em mapeamentos? Acta Bot. Bras., v. 20, n. 2, p. 383394, 2006.

SÃO LUÍS (MA). Lei ${ }^{0}$ 3.253, de 29 de dezembro de 1992. Dispõe sobre o zoneamento, parcelamento, uso e ocupação do solo urbano e dá outras providências, São Luís, Sistema de Leis Municipais, 2019. Disponível em: www.saoluis.ma.gov.br. Acesso em: 06 abr. 2020.

SATHLER, R.; GUERRA, A. J. T.; POLIVANOV, H.; MARÇAL, M. dos S. Erosive processes in urban areas in the Island of Maranhão. Sociedade \& Natureza, Uberlândia, p. 161-173, may. 2005.

SILVA, Q. D. da. Mapeamento geomorfológico da Ilha do Maranhão. 2012. 249 p. Tese (Doutorado em Geografia) - Faculdade de Ciências e Tecnologia, Universidade Estadual Paulista, Presidente Prudente, 2012.

SUERTEGARAY, D. M. A. Tempos Longos. Tempos Curtos. Na Análise da Natureza. Geografares, Vitória, n. 3, p. 159-164, jun. 2002.

SUERTEGARAY, D. M. A.; DE PAULA, C. Q. Geografia e questão ambiental, da teoria à práxis. AMBIENTES, v. 1, n. 1, p. 79-102, 2019.

TRENTIN, R. Mapeamento geomorfológico e caracterização geoambiental da bacia hidrográfica do Rio Itu - oeste do Rio Grande do Sul - Brasil. 2011. 220 p. Tese (Doutorado em Geografia) - Setor de Ciências da Terra, Universidade Federal do Paraná, Curitiba, 2011.

Universidade Federal do Maranhão (UFMA). Estudo de Impacto Ambiental e Relatório de Impacto Ambiental da Refinaria Premium I. v. 2. São Luís: UFMA, 2009.

VALLADARES, G. S. Caracterização química e granulométrica de solos do Golfão maranhense. Acta Amazonica, v. 39, n. 4, p. 923-934, 2009.

Recebido em: 17/04/2020 Aprovado para publicação em: 30/07/2020 